\title{
Antioxidant and hepatoprotective role of selenium against silver nanoparticles
}

\author{
This article was published in the following Dove Press journal: \\ International Journal of Nanomedicine \\ 24 October 2017 \\ Number of times this article has been viewed
}

\author{
Sabah Ansar' \\ Saad MAlshehri \\ Manal Abudawood' \\ Sherifa S Hamed ${ }^{3,4}$ \\ Tansir Ahamad ${ }^{2}$ \\ 'Clinical Laboratory Sciences, Applied \\ Medical Science, King Saud University, \\ Riyadh, Saudi Arabia; ${ }^{2}$ Department of \\ Chemistry, College of Science, King \\ Saud University, Riyadh, Saudi Arabia; \\ ${ }^{3}$ Zoology Department, College of \\ Science, King Saud University, Riyadh, \\ Saudi Arabia; ${ }^{4}$ Zoology Department, \\ Faculty of Science, University \\ of Alexandria, Moharram Bey, \\ Alexandria, Egypt
}

\begin{abstract}
Silver nanoparticles (AgNPs) have attracted the most interest in terms of their potential biomedical and industrial applications. However, these nanoparticles have shown their toxic behavior toward environment, living tissues, and organisms. Selenium (Se), an essential trace element, is necessary for various metabolic processes, including protection against oxidative stress and immune function. The present study was undertaken to evaluate the effect of Se against AgNP-induced hepatic oxidative stress. AgNPs were synthesized and then prepared nanoparticles were characterized using various analytical techniques such as UV-visible spectroscopy, X-ray diffraction, and transmission electron microscopy. Rats were administered AgNPs intraperitoneally ( $5 \mathrm{mg} / \mathrm{kg} /$ day) and Se $(0.2 \mathrm{mg} / \mathrm{kg})$ was given by gavage. AgNP administration induced hepatic damage as indicated by the serum marker enzymes with reduction in levels of glutathione, and decrease in activities of SOD, CAT, and GSH-peroxidase $(P<0.05)$. Decrease in levels of total antioxidant capacity (TAC) and increase in level of $\mathrm{C}$-reactive protein (CRP) was also observed in AgNP-treated group compared to control group. However, Se markedly attenuated AgNP-induced biochemical alterations, levels of TAC, CRP, and serum transaminases (AST, ALT) $(P<0.05)$. Taken together, these findings suggest that administration of AgNPs produces hepatotoxicity in rats, whereas Se supplementation attenuates these effects.
\end{abstract}

Keywords: silver nanoparticles, selenium, antioxidant enzymes, hepatotoxicity, oxidative stress

\section{Introduction}

Silver nanoparticles (AgNPs) undergo several changes when released into the environment. Other then aggregation and agglomeration, there is formation of silver chloride and silver sulfide. The chemical species which are actually present determine the bioavailability and toxicity of silver in the environment. Bioavailability of AgNPs in soil depends on both particle and soil properties. The release of ionic silver has been found to be the main cause of toxicity in humans, in the environment and in other applications.

AgNPs are known for their antibacterial effect and used in various biomedical applications. ${ }^{1}$ However, there is increasing concern related to the biological impact of the use of AgNPs on a large scale, and the possible toxicity to the environment and health. AgNPs' toxicity can accumulate in several organs, thereby causing toxicity, in part via oxidative stress including pulmonary and germ cell toxicity, embryo toxicity, and cell death..$^{2-9}$ Nanoparticle-induced oxidative stress is hypothesized to be the main mechanism regulating the biological effects of these nanoparticles. ${ }^{10,11}$ Toxicity of AgNPs could also be due to release of Ag ions in the system or extensive systemic distribution of $\mathrm{Ag}$ in tissues causing oxidative stress, protein or DNA damage, and apoptotic cell death. ${ }^{12-21}$
Correspondence: Tansir Ahamad Department of Chemistry, College of Science, King Saud University, Riyadh, Saudi Arabia

Email tahamad@ksu.edu.sa
International Journal of Nanomedicine 2017:12 7789-7797

(c) (i) (5) 2017 Ansar et al. This work is published and licensed by Dove Medical Press Limited. The full terms of this license are available at https://www.dovepress.com/terms.ph (c) 1 By $\mathrm{NC}$ and incorporate the Creative Commons Attribution - Non Commercial (unported, v3.0) License (http:///creativecommons.org/licenses/by-nc/3.0/). By accessing the work you hereby accept the Terms. Non-commercial uses of the work are permitted without any further permission from Dove Medical Press Limited, provided the work is properly attributed. For permission hereby accept the Terms. Non-commercial uses of the work are permitted without any further permission from Dove Mer.
for commercial use of this work, please see paragraphs 4.2 and 5 of our Terms (https://www.doveperss.com/terms.php). 
AgNPs' toxicity is based on surface parameters like shape, size, surface charge, purity, and bioavailability..$^{22,23}$ Moreover, nanoparticles like silver are known to induce ROS in various cell types. ${ }^{24,25}$ In addition, several investigations have also revealed that metal nanoparticles show toxicity and cause a wide range of abnormal manifestations in animals and plants. ${ }^{26-28}$ With increased probability of exposure to AgNP, understanding the toxicological mechanisms is very relevant in this technology-driven society. Under normal circumstances, the body is endowed with antioxidant systems which help in combating oxidative stress and toxicity. However, under extreme oxidative challenge, like exposure to toxins or nanoparticles, the antioxidant machineries may lose their specificity and become overwhelmed. Nanoparticle-induced oxidative stress is hypothesized to be the main mechanism regulating the biological effects of AgNPs. ${ }^{11}$

Selenium (Se) is an essential micronutrient, which is well-known for its detoxifying effects in heavy metal exposure. ${ }^{29}$ Se deficiency is associated with many diseases including chronic degenerative diseases, ${ }^{30}$ impaired cognitive function, and neurological disorders. ${ }^{31}$ Se supplementation also protects from various diseases, such as viral infections, ${ }^{32}$ immune system dysfunction, ${ }^{33}$ and neurodegenerative disease. ${ }^{34}$ Se can also restore the activity of important antioxidant enzymes such as glutathione peroxidase (GSH-Px) and Trx reductase. ${ }^{35-38}$

Thus, the protective properties of Se against AgNPinduced hepatotoxicity were investigated in this study, in the hope of shedding light on potential biochemical alterations, the biological responses induced by acute dosing, and to assess cellular responses. To our knowledge this is the first study to show that Se may be an effective agent for protecting cells from AgNP-induced hepatotoxicity.

\section{Materials and method Materials}

Silver nitrate $\left(\mathrm{AgNO}_{3}\right)$, sodium selenite, chitosan, succinaldehyde, polyvinyl alcohol (molecular weight range: $85,000-124,000)$, and trisodium citrate $\left(\mathrm{NaBH}_{4}\right)$ were purchased from Sigma-Aldrich Co. (St Louis, MO, USA). All other chemicals were of laboratory grade and were used as received. All other necessary reagents were of analytical grade and were purchased from Sigma-Aldrich Co.

\section{Preparation of AgNPs}

Chitosan $(2.5 \mathrm{~g})$ and polyvinyl alcohol were dissolved in $30 \mathrm{~mL}$ of $1 \% \mathrm{CH} 3 \mathrm{COOH}$ aqueous solution with continuous sonication until a homogeneous mixture was obtained, and then $1 \mathrm{~mL}$ of succinaldehyde was added dropwise with continuous stirring to ensure homogeneous cross-linking by the polymerization process. Then, $10 \mathrm{~mL}$ of $1 \mathrm{mM} \mathrm{AgNO}_{3}$ was added. The hydrogel containing $\mathrm{AgNO}_{3}$ was transferred into glass tubes and deoxygenated with nitrogen gas for $30 \mathrm{~min}$ at $5 \mathrm{~mL} / \mathrm{min}$, and then $3 \mathrm{~mL}$ of $1 \mathrm{mM} \mathrm{NaBH}_{4}$ was added. The tubes were irradiated in a microwave (Discover ${ }^{\circledR}$ SP System, CEM Corporation, Matthews, NC, USA) under ambient conditions. The AgNPs prepared in the polymer mixture were separated by centrifugation in aqueous solution and dried at room temperature.

\section{Characterization}

AgNPs exhibit unique and tunable optical properties due to their surface plasmon resonance which is dependent on shape, size, and size distribution of the nanoparticles. UV-visible absorption spectrum of AgNPs was recorded on UV-visible spectrophotometer (Shimadzu 1650; Shimadzu Corporation, Kyoto, Japan) using distilled water as a blank solution. The X-ray diffraction (XRD) pattern of the AgNPs was recorded using an X'pert Pro X-ray diffractometer (PANalytical, Almelo, the Netherlands) with $\mathrm{Cu}-\mathrm{Ka}$ radiation. Surface morphology of prepared AgNPs was examined on a field emission scanning electron microscope at $200 \mathrm{kV}$ (JSM-7600F; JEOL, Tokyo, Japan). Transmission electron microscopy (TEM) studies were carried out with a field emission-transmission electron microscope (JEM-2100F; JEOL). The elements present in the samples were determined through energy dispersive spectrometry (EDS) analysis.

\section{Animals}

Male Wistar rats (weighing approximately 150-200 g) were acclimatized for a month prior to experiments. All the animals used in this study were kept in cages in an air conditioned room $\left(72^{\circ} \mathrm{F}-74^{\circ} \mathrm{F}\right)$ with a $12 \mathrm{~h}$ light/dark cycle. The rats were fed commercial pellet feed and given water ad libitum. The study was approved by the Ethical Committee of King Saud University and was carried out in compliance with the declarations of National Research Council, USA for animal care guidelines. The rats were divided into four groups, each group consisting of six animals as follows: control group (distilled water), Se-treated group $(0.2 \mathrm{mg} / \mathrm{kg} /$ day $)$, AgNP-treated group ( $5 \mathrm{mg} / \mathrm{kg} /$ day), and AgNPs-Se-treated group ( $5 \mathrm{mg} / \mathrm{kg}$ /day for AgNPs and $0.2 \mathrm{mg} / \mathrm{kg} /$ day for Se). AgNPs in $0.5 \mathrm{~mL}$ of distilled water were injected intraperitoneally and sodium selenite, as a source of Se, was administered orally once daily for 7 days before AgNPs injection. 
These doses were selected on the basis of an acute toxicity study for AgNPs and sodium selenite (data not shown), well below the LD50 values. Blood samples were collected for biochemical analysis and serum was centrifuged for $10 \mathrm{~min}$ at 3,000 rpm.

Livers were carefully removed for biochemical studies, washed in ice-cold $50 \mathrm{mM}$ Tris-HCl, $\mathrm{pH} 7.4$ and homogenized. The homogenates were centrifuged and the supernatants were used for further experiments. The total protein content in the homogenized tissue was determined by using previously reported method of Lowry et al. ${ }^{39}$

\section{Biochemical assays}

The liver homogenates were used to determine glutathione (GSH) level, ${ }^{40} \mathrm{SOD},{ }^{41} \mathrm{CAT}$ activity, ${ }^{42}$ and GSH-Px activity. ${ }^{43}$ The levels of total antioxidant capacity (TAC) were quantified using an ELISA kit (CYT 294; EMD Millipore, Billerica, MA, USA), C-reactive protein (CRP) was quantified by ELISA kit (MBS 733414, MyBioSource, San Diego, CA, USA) and serum transaminases (ALT, AST) were determined using Sigma-Aldrich Co. kits (MAC052, MAK055).

\section{Histopathological analysis}

Samples of fragments of fresh livers were fixed in buffered $10 \%$ formalin solution. Thereafter the tissues were dehydrated and cleared using a graded series of ethanol and xylene respectively and embedded in paraffin $\left(58.6^{\circ} \mathrm{C}\right)$. Sections of paraffin blocks were cut by a rotary microtome $(5 \mu \mathrm{m})$ and the sections were stained with hematoxylin and eosin, and were examined and photographed using a photomicroscope (Nikon Corporation, Tokyo, Japan).

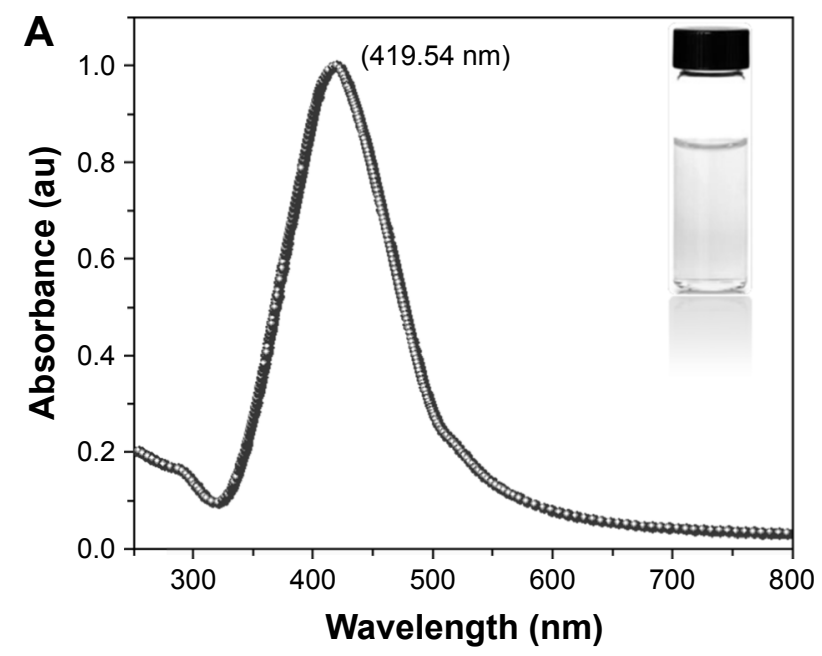

Figure I (A) UV-visible spectra of AgNPs, (B) XRD pattern of AgNPs. Abbreviations: AgNPs, silver nanoparticles; UV, ultraviolet; XRD, X-ray diffraction.

\section{Statistical analysis}

Results were analyzed using SPSS software and expressed as the mean \pm SEM. One-way ANOVA was applied to test for the significance of biochemical data of the different groups followed by parametric paired $t$-test and Duncan's multiple range test wherever appropriate. Results were considered significant when $P \leq 0.05$.

\section{Results \\ Characterization of the AgNPs}

A UV-visible spectrum was used to determine the formation and stability of AgNPs in the polymer matrix as shown in Figure 1A. The result revealed that the maximum absorbance of yellow AgNPs was at $412 \mathrm{~nm}$ due to the surface plasmon absorption of small-sized AgNPs. ${ }^{44}$ The nanoparticles were stable in size and shape, supported by UV-visible spectra which was repeated weekly for 2 weeks.

An XRD method was used to characterize the synthesized AgNPs and the result is shown in Figure 1B. The XRD AgNPs exhibit characteristic peaks at scattering angles $(2 \theta)$ $39.860,44.23,64.47 \mathrm{o}$, and 77.33 corresponding to $(1,1,1)$, $(2,0,0),(2,2,0)$, and $(3,1,1)$ planes, respectively and support the face-centered cubic (fcc) structure of AgNPs. The crystalline fcc structure of AgNPs can be assigned to standard JCPDS Card 89-3722. The lattice plane reflection at 39.860 was used to calculate the average size of AgNPs according to the Debye-Scherrer equation and the crystallite size of AgNPs was estimated to be approximately $18 \mathrm{~nm}$, which is also further supported by TEM results.

The TEM and high-resolution transmission electron microscopy (HRTEM) images of AgNPs are shown in Figure 2.

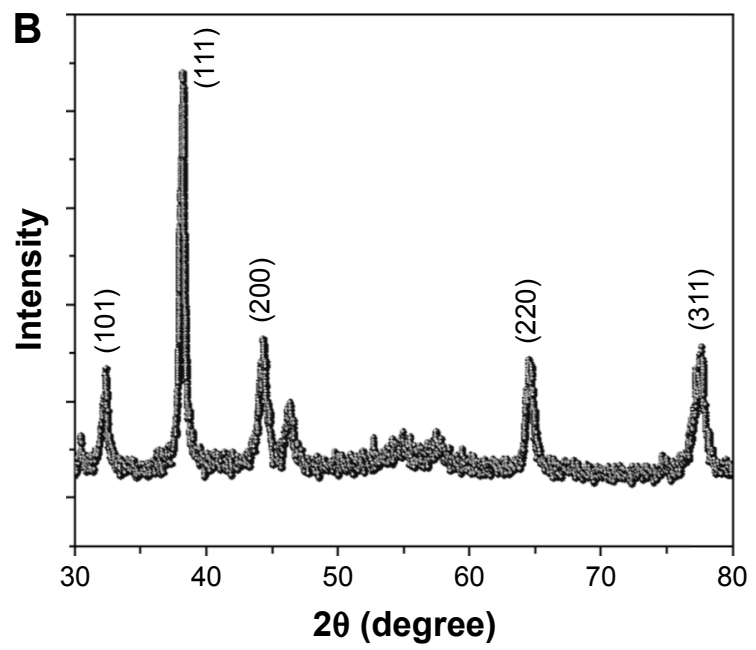



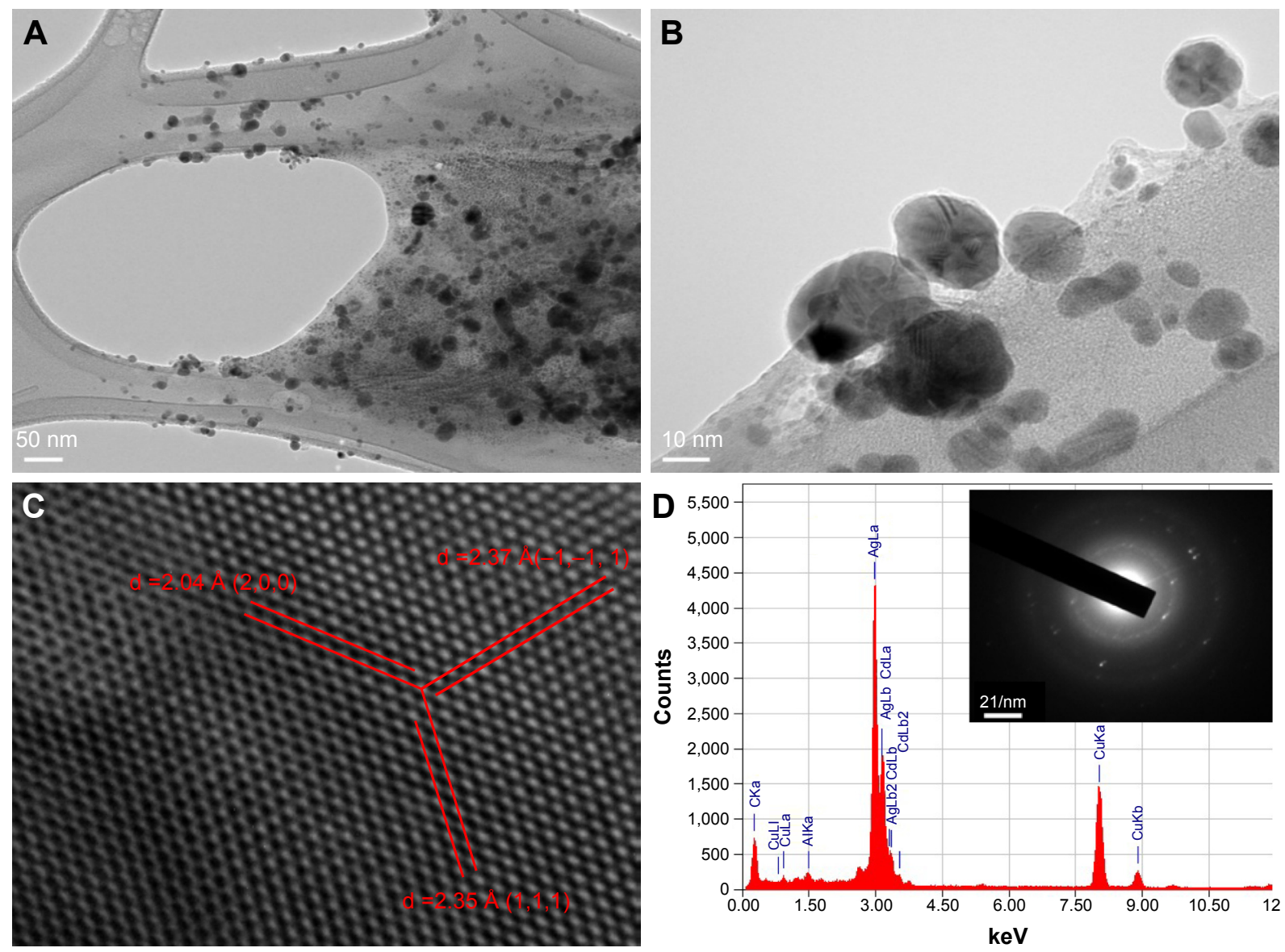

Figure 2 (A, B) TEM images of AgNPs, (C) HRTEM of AgNPs, (D) SAED pattern of AgNPs.

Abbreviations: TEM, transmission electron microscopy; AgNPs, silver nanoparticles; HRTEM, high-resolution transmission electron microscopy; SAED, selected area (electron) diffraction.

In Figure $2 \mathrm{~A}$ and $\mathrm{B}$, the $\mathrm{AgNPs}$ were seen to have a diameter of approximately $15-20 \mathrm{~nm}$, the particle size distribution histograms of AgNPs were almost Gaussian and the mean particle size was $17.5 \mathrm{~nm}$, calculated from 120 nanoparticles. The results of TEM revealed that the synthesized AgNPs were almost monodispersed. The lattice fringes in processed highresolution TEM images (Figure 2C) show that the AgNPs are single crystals, and also reveal that the particles have a lattice d-spacing of 2.04, 2.35, and $2.37 \AA$ and their indices (hkl) are assigned to $\{2,0,0\},\{1,1,1\}$, and $\{-1,-1,1\} \vee$ planes of $A g$, respectively, indicating an fcc crystalline structure. ${ }^{45-48}$

The elemental composition of sample over the grid by EDS (Figure 2D) revealed that the main component of the sample is $\mathrm{Ag}$, although the $\mathrm{C}$ and $\mathrm{Cu}$ peak could primarily come from the lacey-carbon of the TEM grid. On the other hand, the presence of lightest elements such as $\mathrm{H}$ are not detected by EDS technique. ${ }^{49}$ The insert of Figure 2D shows a representative selected area (electron) diffraction (SAED) pattern of AgNPs. In this pattern, spotty rings ascribed to the $\{111\},\{200\},\{220\},\{311\}$, and $\{331\}$ planes of fcc metallic silver (JCPDS 87-0720) are clearly observed. ${ }^{46,47}$

\section{Effect of Se on serum ALT and AST}

The present study explored the effect of Se on AgNP-induced hepatic toxicity. The activities of AST and ALT were significantly increased in serum of rats treated with AgNP compared

Table I Effect of Se on AgNP-induced serum AST and ALT levels

\begin{tabular}{lllll}
\hline Experimental groups & & & & \\
\hline Parameters & Control (I) & AgNP (2) & Se (3) & Se + AgNP (4) \\
\hline AST (IU/L) & $205.18 \pm 24.12$ & $341.12 \pm 32.32^{*}$ & $203.43 \pm 37.37$ & $242.11 \pm 36.45^{* *}$ \\
ALT (IU/L) & $125.34 \pm 21.32$ & $250.40 \pm 31.25^{*}$ & $120.12 \pm 31.35$ & $167.55 \pm 23.12^{* *}$ \\
\hline
\end{tabular}

Notes: All values are mean \pm SEM, $n=6$. Group I vs $2(* p<0.05)$; group 2 vs $4(* * p<0.05)$.

Abbreviations: Se, selenium; AgNP, silver nanoparticle. 
to their respective control $(P<0.5)$ (Table 1). Pretreatment of rats with Se in AgNP-treated group caused reduction in the levels of AST and ALT $(P<0.5)$. This indicates that supplementation of Se normalized the AST and ALT activity in serum compared to AgNP-treated rats. However, activities of AST and ALT did not show any change in group 3 rats (Se-treated only) compared to control group.

\section{Effect of Se on hepatic antioxidant defense system}

AgNPs' treatment led to a decrease in the activity of GSH level, as shown in Figure 3A. However, pretreatment with Se (group 4) led to an increase in the levels of GSH as compared to group $2(P<0.05)$. As shown in Figure 3B-D, AgNPs' administration (group 2) also led to a decrease in activities of antioxidant enzymes: SOD, CAT, and GSH-Px relative to the control rats $(P<0.05)$. On the other hand, Se pretreatment (group 4) increased the activities of SOD,
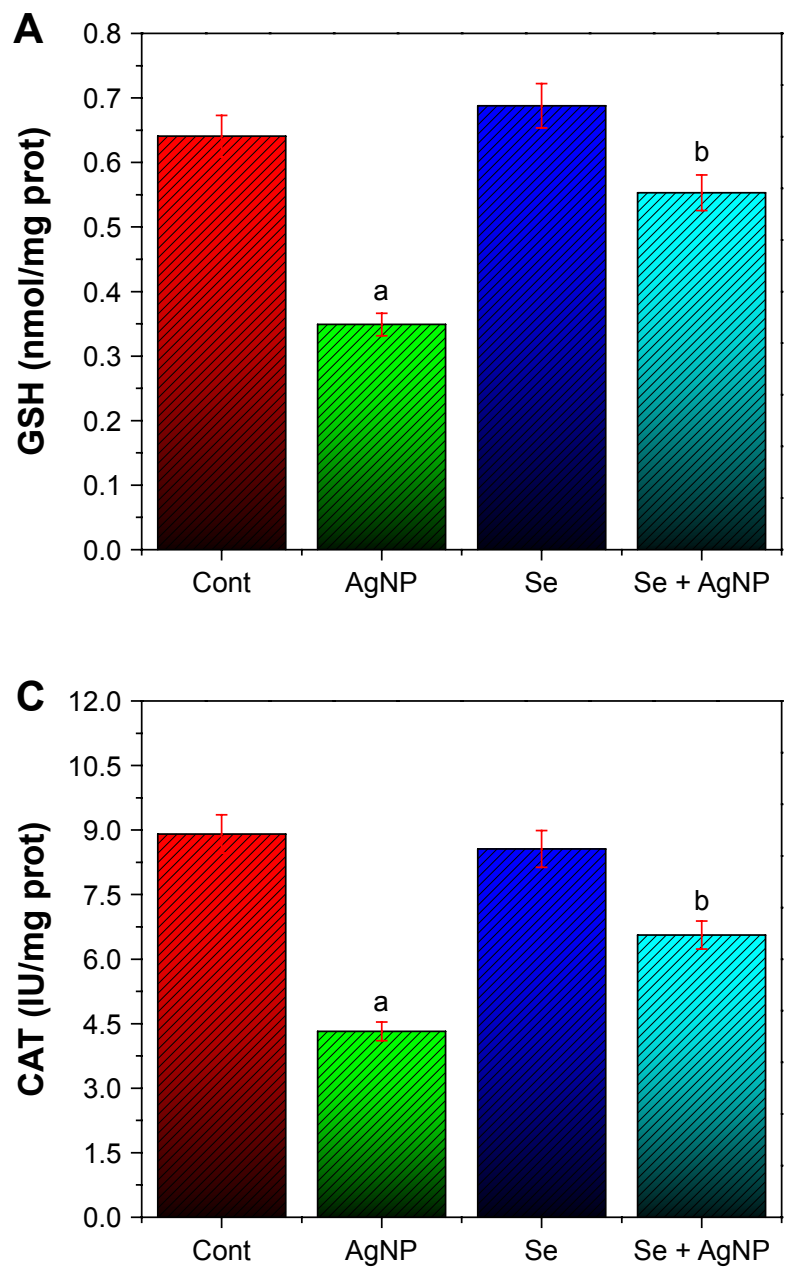

CAT, and GSH-Px significantly $(P<0.05)$ compared to the AgNP group. No change in activities of enzymes was observed in Se pretreated group 3 vs control group. Results indicate that AgNP causes oxidative stress by decreasing levels of antioxidant enzymes compared to control groups. Treatment with Se successfully elevated the activities of SOD, CAT, and GSH-Px significantly, compared to the AgNPs treated group.

\section{Effect of Se on TAC and CRP levels in serum}

AgNPs caused a significant decrease in TAC level compared to control group as shown in Figure 4A. However, Se pretreatment (group 4) elevated TAC significantly $(P<0.05)$ compared to the AgNP group. No change in TAC was observed in Se pretreated group 3 vs control group 1. AgNPs' effect on CRP levels in the serum was also studied (Figure 4B). AgNP treatment in rats resulted in a significant increase in
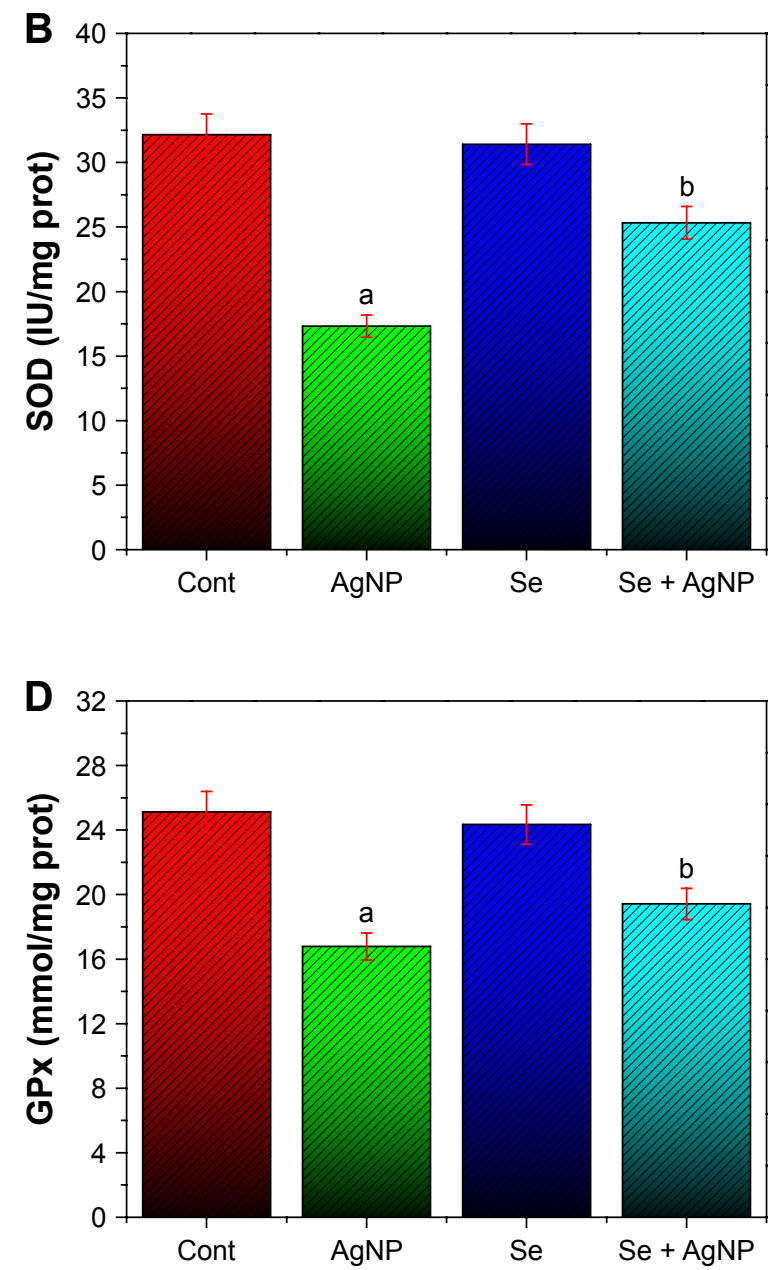

Figure 3 (A) Effect of Se on AgNP-induced GSH levels, the data represent means \pm SEM. (B-D) Influence of Se on AgNP-induced antioxidant levels in the liver compared with their respective control groups, the data represent means \pm SEM. a: $P<0.05$ with respect to the control group (significant). b: $P<0.05$ with respect to AgNP group (significant).

Abbreviations: Se, selenium; AgNP, silver nanoparticle; Cont, control; GSH, glutathione; prot, protein. 

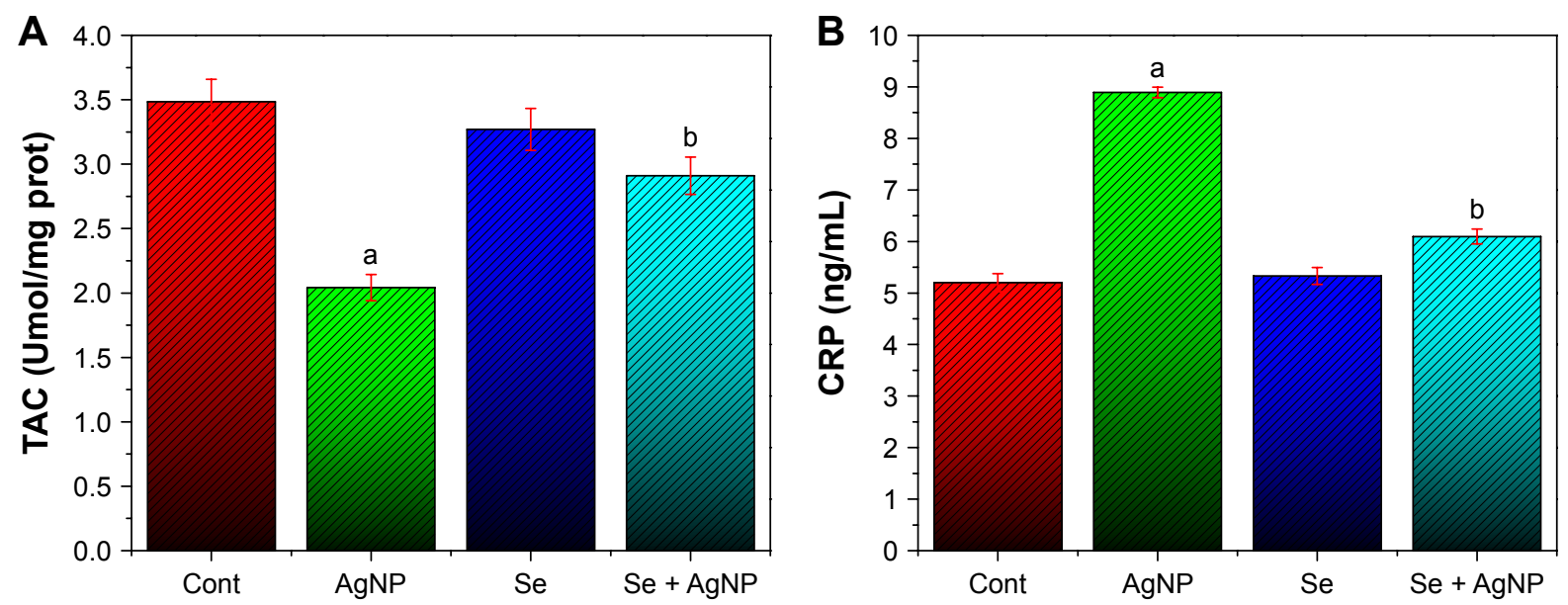

Figure 4 (A, B) Influence of Se on AgNP-induced TAC and CRP levels in serum compared with their respective control groups. The data represent means \pm SEM. a: $P<0.05$ with respect to the control group (significant). b: $P<0.05$ with respect to AgNP group (significant).

Abbreviations: Se, selenium; AgNP, silver nanoparticle; TAC, total antioxidant capacity; CRP, C-reactive protein; Cont, control; prot, protein.

this inflammatory biomarker (group 2 vs group 1). However, pretreatment with Se resulted in a significant decrease in the CRP biomarker compared to group $2(P<0.05)$. Se by itself in group 3 did not affect the CRP levels compared to group 1. These results suggest that AgNPs-induced increase in the inflammatory marker was significantly prevented with the Se pretreatment in these rats $(P<0.05)$.

\section{Histopathological effects on the liver}

The sections of the control liver showed a normal hepatic structure with hepatic lobule and central vein (Figure 5A). Sections of rat livers exposed to AgNPs alone (group 2) showed a disorganized hepatic structure with dilated central vein, hepatocytes with pyknotic nuclei, and Kupffer cells (Figure 5B). Liver sections from Se-treated rats (group 3)
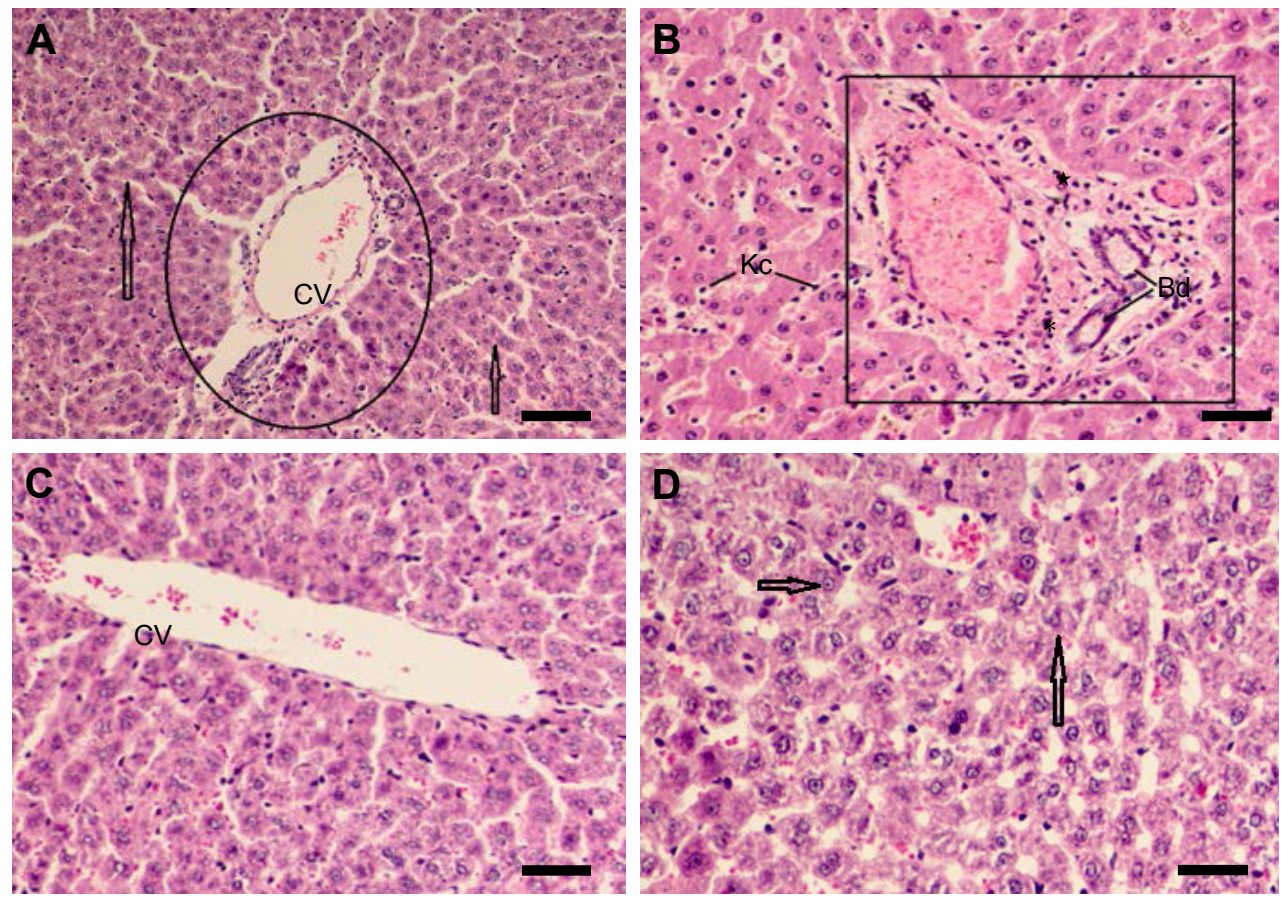

Figure 5 Histological evaluation of Se and AgNPs treatment of rats. (A) Control group, normal liver architecture showing portal area (circle), hepatic strands of eosinophils (arrows), and central vein. (B) AgNPs treated group showing portal tract expansion (square), dense infiltration of mononuclear cells (star), increase in Kupffer cells (Kc), proliferated bile duct (Bd), and accumulation of cells around central vein. (C) Section of rat liver (Se-treated) showing normal hepatocytes and central vein similar to control. (D) Section of rat livers (Se + AgNPs treated) showing normal cellular appearance and decrease in toxicity (arrows). Scale bar $50 \mu m$.

Abbreviations: Se, selenium; AgNPs, silver nanoparticles; CV, central vein. 
showed more organized hepatic strands than group 2 and better hepatic architecture (Figure 5C). Sections from rats of group 4 (Figure 5D), treated with $\mathrm{Se}+\mathrm{AgNPs}$ showed normal architecture of cells and fewer Kupffer cells in comparison to group 2 .

\section{Discussion}

Nanoparticles are used on a daily basis and have several applications in the medical and electronic fields. ${ }^{49}$ The unique physical and chemical properties of AgNPs make them excellent candidates for many purposes in the medical field, including their antimicrobial and anti-inflammatory properties. However, there are reports which suggest that nanosilver can allegedly cause adverse effects on humans as well as the environment. Organisms tend to incorporate nanoparticles within their bodies mainly through the gut but can translocate within the body. Increased ROS production after exposure to nanoparticles has been linked in several studies. ${ }^{50-52}$ It has also been reported that oxidative stress seen in different types of cells like fibroblast, muscle, and colon was due to apoptosis induced by exposure to AgNPs. ${ }^{50}$ The formation of free radicals and other toxic oxidizing agents can be prevented using some enzymatic antioxidants such as GSH reductase, CAT, Px, etc.

In the present study, AgNPs treatment led to a decrease in the activity of GSH, and pretreatment with Se increased its levels. GSH is an antioxidant which can quench free radicals or serve as a substrate for other antioxidant enzymes, such as GSH-Px and GSH reductase. The decreased levels of GSH after exposure to AgNPs may be due to complexing of AgNPs with thiol groups or to increasing use of GSH to downplay the effect of free radicals after exposure to the nanoparticles. ${ }^{52,53}$ These nanoparticles have a strong affinity for thiol groups and may therefore predispose to a decrease in GSH content, thereby leading to the formation of complexes between radical species and cellular proteins or other biomolecules. Se is an essential element with beneficial antioxidant property and is a structural component of several enzymes like GSH-Px and Trx reductase, and has been found to have detoxification effects on various heavy metals.

CAT levels were inconsistently altered after exposure to AgNPs, as also observed in previous studies. ${ }^{54}$ Also, AgNPs caused inconsistent reductions in the levels of GSH-Px in serum and tissues, perhaps because the nanoparticles have an affinity for thiol groups. ${ }^{55}$ The alterations in the levels of these enzymes may represent an adaptive mechanism to offset the stress of exposure. Earlier studies have shown that exposure of rats to AgNPs can alter biochemical processes and AgNPs can sequester and accumulate in vital organs, including the kidney, lung, testes, and brain. ${ }^{56-58}$ These data suggest that AgNPs can induce oxidative damage through an ROS-mediated process. However, it remains to be investigated whether AgNPs induce free radicals directly or indirectly through depletion of antioxidant defense mechanisms depending on dose eg, caused by interactions with antioxidant systems. ${ }^{59}$ This may explain why the biochemical alterations caused by AgNPs became more pronounced with longer exposure, and indicates that caution should be exercised in their use for biomedical purposes.

Se treatment, however, reduced CRP level compared with the AgNP intoxicated group. Also, AgNPs caused a significant decrease in TAC level compared to control group. However, Se pretreatment increased TAC levels significantly compared to the AgNP group. Nanoparticles can be toxic and can elicit a lot of tissue responses such as cell activation, generation of ROS, inflammation, and cell death. ${ }^{59,60}$ The elevated levels of CRP indicate the presence of reactive species related to the incidence of many pathological conditions such as coronary heart disease, hypertension, and inflammation. However, pretreatment with Se can effectively counteract oxidative damage caused by scavenging reactive oxygen radicals and protect membrane integrity.

The liver damage as observed in the current study, has been consistent with previous studies reporting toxicity by AgNPs in the hepatic Kupffer cells and endothelial cells lining the sinusoidal spaces. ${ }^{61,62}$ However, it has been concluded that deposition of AgNPs in tissue samples is sizedependent in the liver and kidneys of male and female rats. ${ }^{63,64}$ In this study, Se treatment of AgNPs exposed rats showed alleviation of the histopathological changes in rat livers. Se pretreatment of AgNPs showed a mild restoration of hepatic cellular organization in comparison to the AgNPs treated group. Recently, Se has been shown to interact in the body of mammals, reducing toxicity of certain compounds. ${ }^{65-67}$ It could be that Se administration prevents free radical formation by increasing antioxidant activity of tissue, as evident in our studies, and prevent AgNPs' toxicity.

\section{Conclusion}

AgNPs are used in an increasing number of applications and these compounds are already used in several products like toothpaste and antibacterial gels, without a profound understanding of how the human body will react and respond to sustained exposure. Therefore, future investigations should be conducted to explore the effects of particle size, different 
doses, and chemical composition on cellular and molecular responses in various tissues. Se has been known to be important for the antioxidant defense system of the organism, and has been shown to be protective against various toxic insults. Thus, Se can be used as a therapeutic agent in improving the antioxidant system and reducing tissue toxicity. However, the beneficial effect of Se was expressed in a very narrow dosage range, and the high and low doses of Se may be connected with pathological manifestations.

\section{Acknowledgment}

The authors extend their appreciation to the Deanship of Scientific Research at King Saud University for funding this work through the Research Group No RG-1438-026.

\section{Disclosure}

The authors report no conflicts of interest in this work.

\section{References}

1. Varaprasad K, Vimala K, Ravindra S, Narayana Reddy N, Venkata Subba Reddy G, Mohana Raju K. Fabrication of silver nanocomposite films impregnated with curcumin for superior antibacterial applications. J Mater Sci Mater Med. 2011;22(8):1863-1872.

2. Shanthi S, Jayaseelan BD, Velusamy P, Vijayakumar S, Chih CT, Vaseeharan B. Biosynthesis of silver nanoparticles using a probiotic Bacillus licheniformis Dahb1 and their antibiofilm activity and toxicity effects in Ceriodaphnia cornuta. Microb Pathog. 2016;93:70-77.

3. Lee SW, Park SY, Kim Y, Im H, Choi J. Effect of sulfidation and dissolved organic matters on toxicity of silver nanoparticles in sediment dwelling organism, Chironomus riparius. Sci Total Environ. 2016;553: $565-573$.

4. Han JW, Jeong JK, Gurunathan S, et al. Male- and female-derived somatic and germ cell-specific toxicity of silver nanoparticles in mouse. Nanotoxicology. 2016;10(3):361-373.

5. Braakhuis HM, Giannakou C, Peijnenburg WJ, Vermeulen J, van Loveren H, Park MV. Simple in vitro models can predict pulmonary toxicity of silver nanoparticles. Nanotoxicology. 2016;10(6):770-779.

6. Braakhuis HM, Cassee FR, Fokkens PH, et al. Identification of the appropriate dose metric for pulmonary inflammation of silver nanoparticles in an inhalation toxicity study. Nanotoxicology. 2016;10(1): $63-73$.

7. Boudreau MD, Imam MS, Paredes AM, et al. Differential effects of silver nanoparticles and silver ions on tissue accumulation, distribution, and toxicity in the Sprague Dawley rat following daily oral gavage administration for 13 weeks. Toxicol Sci. 2016;150(1):131-160.

8. Banan A, Kalbassi Masjed Shahi MR, Bahmani M, Yazdani Sadati MA. Toxicity assessment of silver nanoparticles in Persian sturgeon (Acipenser persicus) and starry sturgeon (Acipenser stellatus) during early life stages. Environ Sci Pollut Res Int. 2016;23(10):10139-10144.

9. Asmonaite G, Boyer S, Souza KB, Wassmur B, Sturve J. Behavioural toxicity assessment of silver ions and nanoparticles on zebrafish using a locomotion profiling approach. Aquat Toxicol. 2016;173:143-153.

10. Klein S, Dell'Arciprete ML, Wegmann M, et al. Oxidized silicon nanoparticles for radiosensitization of cancer and tissue cells. Biochem Biophys Res Commun. 2013;434(2):217-222.

11. Klein S, Sommer A, Distel LV, Neuhuber W, Kryschi C. Superparamagnetic iron oxide nanoparticles as radiosensitizer via enhanced reactive oxygen species formation. Biochem Biophys Res Commun. 2012; 425(2):393-397.
12. Arora S, Jain J, Rajwade JM, Paknikar KM. Interactions of silver nanoparticles with primary mouse fibroblasts and liver cells. Toxicol Appl Pharmacol. 2009;236(3):310-318.

13. Arora S, Jain J, Rajwade JM, Paknikar KM. Cellular responses induced by silver nanoparticles: in vitro studies. Toxicol Lett. 2008; 179(2):93-100.

14. Hsin YH, Chen CF, Huang S, Shih TS, Lai PS, Chueh PJ. The apoptotic effect of nanosilver is mediated by a ROS- and JNK-dependent mechanism involving the mitochondrial pathway in NIH3T3 cells. Toxicol Lett. 2008;179(3):130-139.

15. Gopinath P, Gogoi SK, Sanpui P, Paul A, Chattopadhyay A, Ghosh SS. Signaling gene cascade in silver nanoparticle induced apoptosis. Colloids Surf B Biointerfaces. 2010;77(2):240-245.

16. Marin S, Vlasceanu GM, Tiplea RE, et al. Applications and toxicity of silver nanoparticles: a recent review. Curr Top Med Chem. 2015;15(16):1596-1604.

17. Zhao X, Ibuki Y. Evaluating the toxicity of silver nanoparticles by detecting phosphorylation of histone $\mathrm{H} 3$ in combination with flow cytometry side-scattered light. Environ Sci Technol. 2015;49(8): 5003-5012.

18. Yun JW, Kim SH, You JR, et al. Comparative toxicity of silicon dioxide, silver and iron oxide nanoparticles after repeated oral administration to rats. $J$ Appl Toxicol. 2015;35(6):681-693.

19. Seiffert J, Hussain F, Wiegman C, et al. Pulmonary toxicity of instilled silver nanoparticles: influence of size, coating and rat strain. PLoS One. 2015;10(3):e0119726.

20. Mackevica A, Skjolding LM, Gergs A, Palmqvist A, Baun A. Chronic toxicity of silver nanoparticles to Daphnia magna under different feeding conditions. Aquat Toxicol. 2015;161:10-16.

21. Volker C, Kampken I, Boedicker C, Oehlmann J, Oetken M. Toxicity of silver nanoparticles and ionic silver: comparison of adverse effects and potential toxicity mechanisms in the freshwater clam Sphaerium corneum. Nanotoxicology. 2015;9(6):677-685.

22. Fubini B, Ghiazza M, Fenoglio I. Physico-chemical features of engineered nanoparticles relevant to their toxicity. Nanotoxicology. 2010; 4:347-363.

23. Tantra R, Knight A. Cellular uptake and intracellular fate of engineered nanoparticles: a review on the application of imaging techniques. Nanotoxicology. 2011;5(3):381-392.

24. Choi JE, Kim S, Ahn JH, et al. Induction of oxidative stress and apoptosis by silver nanoparticles in the liver of adult zebrafish. Aquat Toxicol. 2010;100(2):151-159.

25. Park EJ, Yi J, Kim Y, Choi K, Park K. Silver nanoparticles induce cytotoxicity by a Trojan-horse type mechanism. Toxicol In Vitro. 2010; 24(3):872-878.

26. Gao J, Sepulveda MS, Klinkhamer C, Wei A, Gao Y, Mahapatra CT. Nanosilver-coated socks and their toxicity to zebrafish (Danio rerio) embryos. Chemosphere. 2015;119:948-952.

27. Ahamed M, Alsalhi MS, Siddiqui MK. Silver nanoparticle applications and human health. Clin Chim Acta. 2010;411(23-24):1841-1848.

28. Ahamed M, Posgai R, Gorey TJ, Nielsen M, Hussain SM, Rowe JJ. Silver nanoparticles induced heat shock protein 70 , oxidative stress and apoptosis in Drosophila melanogaster. Toxicol Appl Pharmacol. 2010;242(3):263-269.

29. Ikemoto T, Kunito T, Tanaka H, Baba N, Miyazaki N, Tanabe S. Detoxification mechanism of heavy metals in marine mammals and seabirds: interaction of selenium with mercury, silver, copper, zinc, and cadmium in liver. Arch Environ Contam Toxicol. 2004;47(3):402-413.

30. Rayman MP. The importance of selenium to human health. Lancet. 2000;356(9225):233-241.

31. Pillai R, Uyehara-Lock JH, Bellinger FP. Selenium and selenoprotein function in brain disorders. IUBMB Life. 2014;66(4):229-239.

32. Look MP, Rockstroh JK, Rao GS, et al. Serum selenium, plasma glutathione (GSH) and erythrocyte glutathione peroxidase (GSH-Px)-levels in asymptomatic versus symptomatic human immunodeficiency virus-1 (HIV-1)-infection. Eur J Clin Nutr. 1997;51(4):266-272. 
33. Ansari MA, Ahmad AS, Ahmad M, et al. Selenium protects cerebral ischemia in rat brain mitochondria. Biol Trace Elem Res. 2004;101(1):73-86.

34. Zafar KS, Siddiqui A, Sayeed I, Ahmad M, Salim S, Islam F. Dosedependent protective effect of selenium in rat model of Parkinson's disease: neurobehavioral and neurochemical evidences. J Neurochem. 2003;84(3):438-446.

35. Islam F, Zia S, Sayeed I, Zafar KS, Ahmad AS. Selenium-induced alteration of lipids, lipid peroxidation, and thiol group in circadian rhythm centers of rat. Biol Trace Elem Res. 2002;90(1-3):203-214.

36. Venardos K, Harrison G, Headrick J, Perkins A. Selenium supplementation and ischemia-reperfusion injury in rats. Redox Rep. 2004;9(6): 317-320.

37. Vanderlelie J, Venardos K, Perkins AV. Selenium deficiency as a model of experimental pre-eclampsia in rats. Reproduction. 2004;128(5): 635-641.

38. Venardos K, Harrison G, Headrick J, Perkins A. Effects of dietary selenium on glutathione peroxidase and thioredoxin reductase activity and recovery from cardiac ischemia-reperfusion. J Trace Elem Med Biol. 2004;18(1):81-88.

39. Lowry OH, Rosebrough NJ, Farr AL, Randall RJ. Protein measurement with the Folin phenol reagent. J Biol Chem. 1951;193(1):265-275.

40. Ellman GL. Tissue sulfhydryl groups. Arch Biochem Biophys. 1959; 82(1):70-77.

41. Nishikimi M, Appaji N, Yagi K. The occurrence of superoxide anion in the reaction of reduced phenazine methosulfate and molecular oxygen. Biochem Biophys Res Commun. 1972;46(2):849-854.

42. Aebi H. Catalase in vitro. Methods Enzymol. 1984;105:121-126.

43. Paglia DE, Valentine WN. Studies on the quantitative and qualitative characterization of erythrocyte glutathione peroxidase. J Lab Clin Med. 1967;70(1):158-169.

44. Jovanovic SP, Syrgiannis Z, Markovic ZM, et al. Modification of structural and luminescence properties of graphene quantum dots by gamma irradiation and their application in a photodynamic therapy. ACS Appl Mater Interfaces. 2015;7(46):25865-25874.

45. Maryan AS, Montazer M, Harifi T. Synthesis of nano silver on cellulosic denim fabric producing yellow colored garment with antibacterial properties. Carbohydr Polym. 2015;115:568-574.

46. MacDonald DG, Kubel C, Corrigan JF. Ferrocenyl functionalized silverchalcogenide nanoclusters. Inorg Chem. 2011;50(8):3252-3261.

47. Wan X, Liang X, Zhang C, et al. Morphology controlled syntheses of $\mathrm{Cu}$-doped $\mathrm{ZnO}$, tubular $\mathrm{Zn}(\mathrm{Cu}) \mathrm{O}$ and $\mathrm{Ag}$ decorated tubular $\mathrm{Zn}(\mathrm{Cu}) \mathrm{O}$ microcrystals for photocatalysis. Chemical Engineering Journal. 2015;272:58-68.

48. Liu T, Li B, Hao Y, Han F, Zhang L, Hu L. A general method to diverse silver/mesoporous-metal-oxide nanocomposites with plasmonenhanced photocatalytic activity. Appl Catal B. 2015;165:378-388.

49. Amir M, Singh E. Some new N-substituted alpha-aryl/alkyl succinimides as possible anticonvulsants. Pharmazie. 1991;46(10):705-707.

50. Shipway AN, Katz E, Willner I. Nanoparticle arrays on surfaces for electronic, optical, and sensor applications. Chemphyschem. 2000;1(1): 18-52.

51. Foldbjerg R, Olesen P, Hougaard M, Dang DA, Hoffmann HJ, Autrup H. PVP-coated silver nanoparticles and silver ions induce reactive oxygen species, apoptosis and necrosis in THP-1 monocytes. Toxicol Lett. 2009;190(2):156-162.
52. Srivastava M, Singh S, Self WT. Exposure to silver nanoparticles inhibits selenoprotein synthesis and the activity of thioredoxin reductase. Environ Health Perspect. 2012;120(1):56-61.

53. Adeyemi OS, Sulaiman FA. Biochemical and morphological changes in Trypanosoma brucei brucei-infected rats treated with homidium chloride and diminazene aceturate. J Basic Clin Physiol Pharmacol. 2012;23(4):179-183.

54. Lovric J, Bazzi HS, Cuie Y, Fortin GR, Winnik FM, Maysinger D. Differences in subcellular distribution and toxicity of green and red emitting CdTe quantum dots. J Mol Med (Berl). 2005;83(5):377-385.

55. Srivastava M, Mallard C, Barke T, Hancock LE, Self WT. A seleniumdependent xanthine dehydrogenase triggers biofilm proliferation in Enterococcus faecalis through oxidant production. J Bacteriol. 2011; 193(7):1643-1652.

56. Tang J, Xiong L, Wang S, et al. Distribution, translocation and accumulation of silver nanoparticles in rats. J Nanosci Nanotechnol. 2009;9(8):4924-4932.

57. Song KS, Sung JH, Ji JH, et al. Recovery from silver-nanoparticleexposure-induced lung inflammation and lung function changes in Sprague Dawley rats. Nanotoxicology. 2013;7(2):169-180.

58. Lee JH, Kim YS, Song KS, et al. Biopersistence of silver nanoparticles in tissues from Sprague-Dawley rats. Part Fibre Toxicol. 2013;10:36.

59. Piao MJ, Kang KA, Lee IK, et al. Silver nanoparticles induce oxidative cell damage in human liver cells through inhibition of reduced glutathione and induction of mitochondria-involved apoptosis. Toxicol Lett. 2011;201(1):92-100.

60. Huang CC, Aronstam RS, Chen DR, Huang YW. Oxidative stress, calcium homeostasis, and altered gene expression in human lung epithelial cells exposed to $\mathrm{ZnO}$ nanoparticles. Toxicol In Vitro. 2010;24(1): 45-55.

61. Recordati C, De Maglie M, Bianchessi S, et al. Tissue distribution and acute toxicity of silver after single intravenous administration in mice: nano-specific and size-dependent effects. Part Fibre Toxicol. 2016;13:12.

62. Sarhan OM, Hussein RM. Effects of intraperitoneally injected silver nanoparticles on histological structures and blood parameters in the albino rat. Int J Nanomedicine. 2014;9:1505-1517.

63. Kim YS, Song MY, Park JD, et al. Subchronic oral toxicity of silver nanoparticles. Part Fibre Toxicol. 2010;7:20.

64. Austin CA, Umbreit TH, Brown KM, et al. Distribution of silver nanoparticles in pregnant mice and developing embryos. Nanotoxicology. 2012;6:912-922.

65. Sun LH, Zhang NY, Zhu MK, Zhao L, Zhou JC, Qi DS. Prevention of aflatoxin B1 hepatoxicity by dietary selenium is associated with inhibition of cytochrome P450 isozymes and up-regulation of 6 selenoprotein genes in chick liver. $J$ Nutr. Epub 2016 Mar 9.

66. Bitiktas S, Tan B, Batakci M, Kavraal S, Dursun N, Suer C. Effects of selenium treatment on 6-n-propyl-2-thiouracil-induced impairment of long-term potentiation. Neurosci Res. 2016;109:70-76.

67. Abarikwu SO, Adebayo OL, Otuechere CA, Iserhienrhien BO, Badejo TA Selenium and rutin alone or in combination do not have stronger protective effects than their separate effects against cadmium-induced renal damage. Pharm Biol. 2016;54(5):896-904.
International Journal of Nanomedicine

\section{Publish your work in this journal}

The International Journal of Nanomedicine is an international, peerreviewed journal focusing on the application of nanotechnology in diagnostics, therapeutics, and drug delivery systems throughout the biomedical field. This journal is indexed on PubMed Central, MedLine, CAS, SciSearch $\AA$, Current Contents ${ }^{\circledR} /$ Clinical Medicine,

\section{Dovepress}

Journal Citation Reports/Science Edition, EMBase, Scopus and the Elsevier Bibliographic databases. The manuscript management system is completely online and includes a very quick and fair peer-review system, which is all easy to use. Visit http://www.dovepress.com/ testimonials.php to read real quotes from published authors. 